\title{
The combinatorics of medications precludes evidence-based algorithms for therapy
}

\author{
D. Rodbard
}

Received: 2 August 2010 /Accepted: 5 August 2010 /Published online: 12 September 2010

(C) Springer-Verlag 2010

Keywords Algorithms · Clinical decision support .

Combinatorics · Evidence-based guidelines .

Pharmacotherapy · Treatment regimens .

Type 2 diabetes mellituss

\section{Abbreviations \\ DPP-4 Dipeptidyl peptidase 4 \\ GLP-1 Glucagon-like peptide 1}

To the Editor: In the July 2010 issue of Diabetologia, Schernthaner et al. [1] and Nolan [2] argue that algorithms for the management of patients with type 2 diabetes should be 'evidence based'. I would argue that it is not feasible to have an evidence-based algorithm in view of the fact that there are more than 100 different treatment regimens when one is dealing with combinations of eight classes of therapeutic agent. The number of possible transitions between treatment regimens is even larger. In contrast, guidelines such as those produced by the American Association of Clinical Endocrinologists [3], the American Diabetes Association [4], the Canadian Diabetes Association [5] and others should be evidence based.

There are currently at least eight classes of medications for therapy of diabetes: biguanides, dipeptidyl peptidase-4 (DPP-4) inhibitors, glucagon-like peptide 1 (GLP-1)

\section{Rodbard $(\triangle)$}

Biomedical Informatics Consultants,

10113 Bentcross Drive,

Potomac, MD 20854-4721, USA

e-mail: drodbard@comcast.net analogues, sulfonylureas, glinides, thiazolidinediones, $\alpha 1$ glucosidase inhibitors and insulin. Colesevelam and bromocriptine have also been approved by the US Food and Drug Administration for treatment of diabetes in the USA. Additional classes of medications are in advanced clinical testing. The impossibility of having evidence-based algorithms can be appreciated the moment one considers the number of combinations and permutations of therapeutic regimens involving eight classes of medications used as mono-, dual, triple, or, occasionally, quadruple therapy. This results in more than 100 possible combinations of agents (Table 1).

Even if we exclude combinations that are not approved (e.g. GLP-1 analogues combined with insulin) and combinations of agents that have similar mechanisms of action (e.g. sulfonylureas and glinides, or DPP-4 inhibitors and GLP-1 analogues) and exclude all but a few cases of quadruple therapy, we still obtain more than 60 different types of regimen [8]. This does not even take into account that there are at least three major sulfonylureas, two types of metformin (if one considers 'extended release' as a separate medication), two glinides, three commercially available DPP-4 inhibitors, two GLP-1 analogues, multiple forms of insulin (regular human insulin, NPH, insulin detemir [B29Lys( $\varepsilon$-tetradecanoyl),desB30 human insulin], insulin glargine [A21Gly,B31Arg,B32Arg human insulin], insulin aspart [B28Asp human insulin], insulin lispro [B28Lys,B29Pro human insulin], insulin glulisine, and several biphasic mixtures of regular human insulin and NPH and of insulin aspart or insulin lispro with protamine), and still more brand names for the generic compounds. When these options are considered, one encounters a further combinatorial explosion. 
Table 1 Combinatorics of multiple (eight) classes of therapeutic agents

\begin{tabular}{ll}
\hline Number of Medications & $\begin{array}{l}\text { Number of combinations } \\
\text { of therapeutic agents }\end{array}$ \\
\hline 0 & 1 \\
1 & 8 \\
2 & $28=(8 \times 7) /(1 \times 2)$ \\
3 & $56=(8 \times 7 \times 6) /(1 \times 2 \times 3)$ \\
4 & $70=(8 \times 7 \times 6 \times 5) /(1 \times 2 \times 3 \times 4)$ \\
Total & 163 \\
\hline
\end{tabular}

It is not economically or logistically feasible to conduct clinical trials that would examine all (or even a majority) of these possibilities in various subsets of patients (e.g. patients with different levels of glycaemic control $\left[\mathrm{HbA}_{1 \mathrm{c}}\right]$, duration of diabetes, levels of adherence, willingness to use injectable medications, levels of education, presence of comorbidities and complications, use of medications for other conditions, and willingness and ability to use frequent self-monitoring of blood glucose intelligently). Hence, it is not possible to collect the necessary clinical data to generate evidence-based algorithms. Evidence-based guidelines are possible and are available [3-5], and provide a foundation for the logic underlying algorithms [6-8].

Duality of interest The author declares that there is no duality of interest associated with this manuscript.

\section{References}

1. Schernthaner G, Barnett AH, Betteridge DJ (2010) Is the ADA/ EASD algorithm for the management of type 2 diabetes (January 2009) based on evidence or opinion? A critical analysis. Diabetologia 53:1258-1269

2. Nolan JJ (2010) Consensus guidelines, algorithms and care of the individual patient with type 2 diabetes. Diabetologia 53:12471249; erratum 53:2078

3. Rodbard HW, Blonde L, Braithwaite SS et al (2007) AACE Diabetes Mellitus Clinical Practice Guidelines Task Force. American Association of Clinical Endocrinologists medical guidelines for clinical practice for the management of diabetes mellitus. Endocr Pract 13 (Suppl 1):1-68, Available from www.aace.com/pub/pdf/guidelines/ DMGuidelines2007.pdf, accessed 28 August 2010

4. American Diabetes Association (2010) Standards of medical care in diabetes-2010. Diabetes Care 33(Suppl 1):S11-S61, Available from http://care.diabetesjournals.org/content/33/Supplement_1/S11. full.pdf $+\mathrm{html}$, accessed 28 August 2010

5. Woo V (2009) Important differences: Canadian Diabetes Association 2008 clinical practice guidelines and the consensus statement of the American Diabetes Association and the European Association for the Study of Diabetes. Diabetologia 52:552-553, author reply $554-555$

6. Rodbard HW, Jellinger PS, Davidson JA et al (2009) Statement by an American Association of Clinical Endocrinologists/American College of Endocrinology consensus panel on type 2 diabetes mellitus: an algorithm for glycemic control. Endocr Pract 15:540 559 , erratum in $15: 768-770$ (the updated/corrected version is available from www.aace.com/pub/pdf/GlycemicControlAlgorithm. pdf, accessed 28 August 2010)

7. Inzucchi SE (2010) Diabetes facts and guidelines, 2010-2011. Yale Diabetes Center, New Haven, pp 71-79. Available from http:// medicine.yale.edu/intmed/endocrin/Images/695_21366_Takeda_ Yale_KLL_tcm314-50135.PDF, accessed 28 August 2010

8. Rodbard D, Vigersky RA (2010) Design and development of a computer assisted clinical decision support system to help physicians manage patients with type 2 diabetes mellitus. Diabetologia 53(Suppl 1):S414 (Abstract) 